\title{
Bridge Over Troubled Water: A Teacher Education Program's Emergent Methods for Constructing an Online Community of Practice During a Global Pandemic
}

\author{
Patricia Rand \\ Clarkson University \\ Catherine Snyder \\ Clarkson University
}

With the sudden shift to emergency remote instruction during the COVID-19 global pandemic in the spring of 2020, teacher education programs were confronted with the dual responsibility of teaching pre-service teachers how to teach and how to teach in synchronous $P-12$ classroom settings utilizing educational technologies. Building a community of practice (CoP) and attending to P-12 students' socio-emotional health and learning were the backdrop to a Masters of Arts and Teaching (MAT) program as it prepared its teacher candidates for full-year teaching residencies. In this retrospective, researchers reflect on practices for building community in an online setting and strategies for supporting teacher candidates' and P-12 students' socio-emotional learning.

Keywords: teacher education, pre-service, online learning, pandemic, community building

\section{INTRODUCTION}

In the spring of 2020, the educational world was turned upside down, and teaching and learning as we knew it was put on pause...but it wasn't really. Educators still responsible for teaching had to pivot to unfamiliar platforms and pedagogies. Students were still held accountable for learning, but from behind a screen rather than a desk. Luckily, teachers and their students had already-established relationships, so the transition to emergency-remote learning was challenging, but not devastating. The we're all in this together mantra helped us all navigate these unprecedented times.

Fast forward a few months to the beginning of a new academic year, this time, commencing with remote instruction. One of the most important questions plaguing educators then became "How will I get to know my students?" Developing authentic relationships and a community of practice without first meeting faceto-face seems uncomfortable and uncommonplace: would we still have that connection with our students, that sense of community, that we work so hard to establish and maintain throughout the year? As teacher educators, we put a lot of stock in building a community of novice teachers who will support each other throughout our Masters of Arts in Teaching (MAT) program, and begin to assemble their own teaching network. Community building is a tenet of the experience we intentionally craft, deliberately modeled for students to show how to establish their own learning communities. 
What follows is a retrospective analysis exploring how a teacher education program remotely built a community of practice with a group of teacher education candidates who had never met before. The context for this retrospective is a thirty-year-old MAT program that has as its cornerstone an intensive six-week summer induction program. The program was always launched with an overnight excursion to a nearby wilderness area where candidates would test their limits and develop what would become life-long collegial networks. In late spring 2020, the challenge for the faculty loomed large: how to shift our in-person program to an online environment while still creating the community of practice that makes the program so strong.

The MAT program operates on a cohort model and typically recruits candidates with content-specific bachelor's degrees. Most candidates enter the program with little education coursework or teaching experience. The goal each year is to accept a cohort of diverse students representing a wide range of disciplines who have strong content-knowledge in their fields. The summer intensive is followed by an academic year during which students were in their residencies during the day, and in classes in the evening. Students graduate in twelve months with their master's degree and initial state certification.

Built on the National Board Professional Teaching Standards, the program teaches its graduate candidates to put their students first in all their decision making. Mirroring that tenet, the program faculty, most of whom are National Board Certified, also put their students first in all curricular and programmatic decision making. This article discusses the solutions developed by a team of National Board Certified pedagogy teachers who formed an online community of practice in order to prepare the candidates to teach both remotely and in-person in the fall. The challenges and successful strategies are shared.

Once the university decided to move all instruction remotely, the instructors only had a few weeks to restructure the curriculum. The instructional team never vacillated: synchronous instruction was immediately selected over asynchronous, as that most closely coincided with an in-person classroom experience and ability to create a community of practice. The real innovation lay ahead: how would we ensure our students felt they were part of our learning community without ever bringing them together in person?

\section{LITERATURE REVIEW}

\section{Community Building Improves Educational Experiences}

The newly-created online summer program adapted a community of practice (Hou, 2015; Wegner, 1991, 1998) model to support and retain their teacher candidates. A community of practice is most commonly defined with reference to Etienne Wegner-Trayner, the researcher who first identified the phenomenon. Wegner-Trayner's definition of a community of practice $(\mathrm{CoP})$ is "a set of relations among persons, activity, and world over time and in relation with other tangential and overlapping communities of practice. A community of practice is an intrinsic condition for the existence of knowledge, not least because it provides the interpretive support necessary for making sense of its heritage." (Wegner, 1991). He goes on to explain that a CoP situates learning in a social context (1998), much in the same way Lev Vygotsky's theories of learning intertwine social interaction and learning (Knight, 2020; Shabani, 2016; Vygotsky, 1978). According to Wegner-Trayner, a community is both impacted by and impacts the learning taking place (1998).

Wegner-Trayner's four characteristics of CoP aligned with the instructors' vision of the online summer program, encompassing their knowledge funds about their learners as well as their goals for the program. The four characteristics are community, practice, meaning and identity (Wegner, 1988). Community refers to a distinct group of individuals coming together with common learning goals. Practice refers to the actual shared experiences, argot, and social space created by the CoP. In the case of the teacher candidates, this was the daily schedule, teaching labs, and the National Board framework. Finally, meaning making and identity are interconnected as participants in a $\mathrm{CoP}$ construct their learning and share that learning (Wegner, 1998). The impact of that learning, if successful, results in a reformatting of their way of knowing - in this case, their way of knowing what it means to be a teacher and their burgeoning teacher identity (Katide, 2014). Among the goals the instructors had for the teacher candidates was the desire to cultivate in them the ability to translate this $\mathrm{CoP}$ experience to their own P-12 classrooms in the fall. 
This was particularly important because most of the teacher candidates would soon be teaching online themselves, and with mentor teachers who had no experience teaching online. The online Community of Practice (OCoP) environment would also prompt some constraints such as lack of technology, or technological know-how, as well as concomitant anxiety related to learners' confidence in an online space (Baran, 2007, Ekici, 2018; Grossman et al., 2020; Kirschner et al., 2007; Zheng, 2011) Consideration of these factors lead the instructional team to revise their curriculum to support students' technological as well as pedagogical learning. To address the potential for increased anxiety, the instructors implemented several community -building strategies which are shared below. The instructors relied upon the understanding that individuals in an oCoP would likely seek opportunities to share their knowledge as this act of sharing typically results in improved professional self-efficacy (Wasco, 2005).

\section{Social Emotional Learning}

But first, we had to ensure that our education faculty and staff were prepared and equipped to meet the socio-emotional needs of our students in anticipation of COVID-19 era-related anxiety. Social and emotional learning (SEL) is the process of acquiring and applying competencies regarding goal setting, management of emotions, building and maintaining relationships, responsible decision making, and effectively handling intrapersonal and interpersonal situations (Elias et al., 1997; Weissberg, Durlak, Domitrovich, \& Gullotta, 2015; Osher et al., 2016). Attending to and addressing students' socio-emotional needs was not new to us: our program already had in place routine advising meetings, scheduled office hours, an open-door drop-in policy, wellness offerings (yoga, meditation, walks), a university Wellness Center staffed by professionals, and a therapy dog. We monitored and cared for our students' well being while teaching them to do the same for the adolescents with whom they worked and taught. Incorporating formal and informal SEL practices and supports is a cornerstone of our MAT program, and important to the education of teachers and students (Bellocchi, Mills, \& Ritchie, 2016; Reeves \& LeMare, 2017; Yaeger, 2017; Garner, Bender, \& Fedor, 2018; Main, 2018; Stipp, 2019).

For the past two decades, SEL has been on the radar of many school districts and teacher education programs, and at the forefront of many others, incorporated to highlight the role of social competence and school climate (Osher et.al, 2018). Fundamentally, the goals of SEL are promoting supportive, engaging positive learning environments and fostering the development of behavioral and cognitive proficiencies. According to Osher et al. (2018), the five guiding competencies are: self-awareness, self-management, social awareness, relationship skills, and responsible decision making (Elias et al., 1997). These are practices that can be taught, especially through self-reflection, self-assessment, and cooperative learning (Yoder, 2014; Osher et al., 2018).

\section{EMERGENT METHODS FOR CONSTRUCTING AN ONLINE COMMUNITY OF PRACTICE}

\section{Don't Break the Ice, Smash It!}

The MAT program puts a strong emphasis on teacher candidate professional dispositions. For many students in the program, entering a school as a novice colleague is the first step on their professional journey. To support our students with their professional dispositions growth, the program implemented what is referred to as the MAT Exercise at the beginning of each cohort's enrollment. The validated exercise, known as the Dispositions, Attributes, and Proficiencies (DAP) interview, was designed by researcher Sally Ingles as a tool for teacher education programs to support teacher candidates' growth in these areas. The validated DAP instrument consists of a fishbowl interview during which the participants grapple with challenging ethical questions. Each group of five to eight students are observed by four education faculty who take notes based on a complex rubric designed to measure students' abilities in four areas: leadership, oral communication, critical thinking, and human interaction. Each student then meets with one of the evaluators at a later date to receive feedback on how they can improve their skills. This exercise was

typically done in person, with the participants together in a room. Since this was not possible for the summer 2020 cohort, the exercise was adapted for the online environment. The groups were made smaller, four to five students, and the observing faculty turned off their microphones and cameras. 
This new format resulted in some different after effects. In the past, students would have talked about the exercise for a day or two, but it would have then been drowned out by all the other social interactions they were experiencing. Because opportunities to interact in small groups were much more limited, the DAP exercise took on a different role for the students, in addition to being a measurement of their skills. It was an opportunity for them to share their points of view, a common ground they could use to continue conversations in breakout rooms or chats with their classmates. The DAP broke the ice on controversial topics and provided them with a protocol for discussing controversial topics. And, the exercise itself took on new meaning as we all discussed what professional teaching dispositions look like in online environments.

The DAP was a large time commitment for the faculty involved, but proved to be an essential part of getting to know the students. It provided them with a forum to get to know each other, a common point of understanding they could build upon as they worked to build trusting professional relationships.

\section{Model Growth Mindset}

Carol Dweck's work on growth mindset is a foundational concept in the MAT program. Teacher candidates are introduced to it during the first week of the summer program and the vocabulary around growth is actively used by all the faculty. Summer 2020 provided an extraordinary opportunity for the faculty to not only teach growth mindset, but model it themselves. Since many were largely unfamiliar with synchronous online-teaching strategies, the summer represented a period of extraordinary growth for everyone. The faculty made their lesson planning, their discoveries, and their mistakes transparent to the students. When a piece of technology didn't work, or a lesson segment didn't go as planned, the faculty carved out space to discuss that with students, get their feedback and advice, and model what it means to be a teacher who is continually learning and growing.

This was done primarily through what was referred to as the daily debrief. Roughly thirty minutes of each day was reserved for students and faculty to reflect on what they learned that day. The comments were captured by one of the faculty and posted for the candidates to review. Candidates asked the faculty questions, asked each other questions, and highlighted aspects of the day's work that really supported their learning, and aspects that didn't quite make sense or work for them. The daily debrief also allowed the students an opportunity to become comfortable interacting with fellow teachers in a collegial way. The faculty modeled growth mindset as they accepted the students' feedback and asked thoughtful questions about their instruction. While primarily academic in nature, this half hour discussion provided the faculty with the ability to take the pulse of the cohort based on the topics they surfaced. It allowed the faculty to then discuss the extent to which the students understood the day's lesson, and impacted how they approached subsequent lessons.

\section{Don't Only Talk the Talk, but Walk the Walk}

Not only did the faculty encourage a growth mindset for the MAT students, but they also had to muster it up for themselves. For years, we used an experiential activity which helped teach the concept of growth mindset. The students were asked to replicate a paper sculpture from a model they were not allowed to touch, only study. This always served as a challenge, and easily evoked high levels of frustration where many students were undoubtedly confronted by their fixed mindsets. In debriefing the activity, students were able to reflect on their frustration, discouragement, and defeatist attitudes, which helped elucidate how adolescents may react to classroom activities and assessments with similar fixed mindsets. This was always an eye-opening activity which helped the MAT students regulate their mindset moving forward in the graduate program, as well as moderate their students' mindsets in the 7-12 classrooms.

How could we replicate this activity in a remote-learning environment? We needed to figure out a way to give the students a similar experience, virtually. Remembering our university purchased a 360 camera, we reached out to our Instructional Technologist who photographed our paper sculpture and uploaded it as a 3-D image that our students could manipulate on their laptops. Rather than scrapping a tried and true activity, we were able to reconfigure it to adapt to a remote-learning environment and give the students a 
different perspective, using technology, which resulted in similar outcomes. In this respect, having a growth mindset about the shift to remote teaching and learning demonstrated that actions speak louder than words.

\section{How Can We Help You?}

Forefront in our minds was our students' mental health and wellness. Graduate school is difficult enough, but coupled with a global pandemic, we knew we had to be hyper aware of our students' states of mind, vigilant in addressing and meeting their needs, and consistent with our approach of collecting data and information. A year ago, we adopted a Pinterest-inspired routine: a daily check-in board where students self-reported how they were feeling each day. It began as a whiteboard chart where students would place a post-it note, with their name hidden on the reverse, in one of the following six categories: I'm great; I'm ok; I'm just feeling meh; I'm struggling; I'm having a hard time and wouldn't mind a check in; I'm in a dark place and need to speak with someone. One faculty member would track students' placement of their post-it, and if any students indicated they were unwell or needed to speak with someone, one of us would pull that students aside and conference with them individually. We found that giving students this outlet to share their feelings on a daily basis gave us greater insight into their lives and ways in which we could support them. We learned about deaths of friends and family members, chronic health issues, broken relationships, daily struggles with academics, and strained resources this way. In the past, we had no way of knowing what was going through our students' minds, possibly hindering their learning and ability to concentrate, unless they spoke with us after class or during office hours. The daily check-in board offered a window into our students' lives we had little access to before.

\section{FIGURE 1 PRE-COVID DAILY CHECK-IN BOARD}

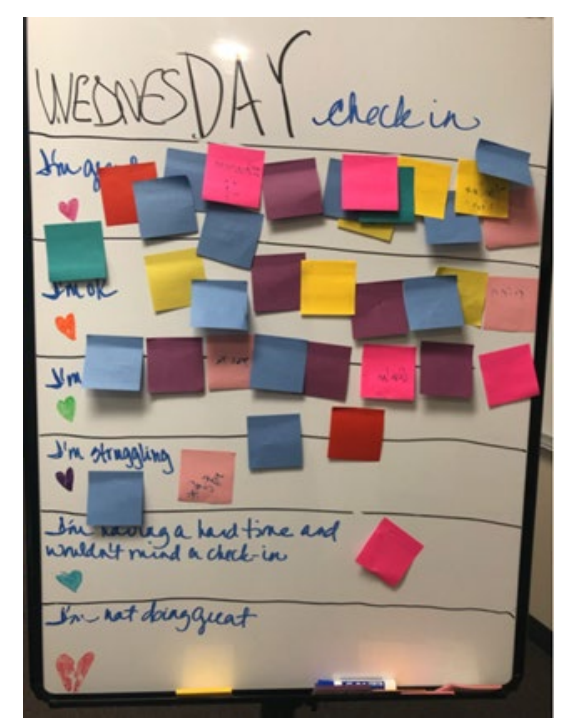

Of course, after a year of being able to address our students' socio-emotional needs in this manner, we were adamant about including the check-in board during remote instruction. We felt this process was more important than ever, given the state of the world and the attention to mental health during times of quarantine and social distancing. We created a Google form, with the same six topics, that students could complete every day. This way, even though we were not meeting or seeing them in person, which eliminated any possibility of informal conversations, we were still keeping a check on their self-reported well being. Even though we never met many of these students in person prior to beginning the summer semester, they were surprisingly willing to share hardships they were enduring or anxieties they were facing, which made it easier for us to support them when necessary. Again, they reported feelings of malaise, losses of loved ones, struggles with academics, and discomforts with pandemic-related issues. Our check-in board was also 
key to building our community: it showed our students that we cared about them as individuals, not just as students, and were concerned about what was happening in their lives, modeling how they should be attuned to adolescents' well-being in their own classrooms.

\section{What's in a Name?}

One of the greatest takeaways of remote synchronous instruction was that it's often the little things that count the most in building community. Initially, we used the naming feature in Zoom for purely administrative purposes. We asked students to enter their first and last names, so we could take attendance. When we were creating discipline-specific breakout groups at the beginning of the semester, we asked them to change their name tags to reflect their content area, before we had them memorized. We asked them to share what they preferred to be called: Patti rather than Patricia; Rich rather than Richard; Mar rather than Marianne. We asked them to let us know which pronouns they preferred, included as an indicator on their nametag.

As the semester progressed, and when we all knew each other's names, disciplines, and pronouns well, we began by beginning each class with a fun descriptor: birth month; favorite candy; favorite season. Students began offering suggestions for naming devices, favorite children's book; favorite tv show; favorite song. By the end of the semester, faculty were naming themselves before class began, and when the students logged in, they had to look around the Zoom room name tags to determine how they would represent themselves that day: favorite vegetable; favorite holiday; favorite drink. Students looked forward each day to discovering the naming conventions and making connections with others in the class based on shared interests. One day, favorite ice cream flavor incited a great discussion about a locally-produced ice cream that was untasted by a few students who were not from the area. This sparked a challenge to go out and taste different flavors of local ice cream and come back to report on whether it deserved the distinction of best. Even though these students had never met in person, they were still able to banter and socialize with each other, just like they would have done before or after class under normal circumstances. They bonded over musical preferences, Netflix binges, and must-eat restaurants. They arranged socially-distanced meetups and played video games online. Truth will out: opening the space and giving the opportunity for building community, students will organically connect, even within a distance-learning environment.

\section{Through the Looking Glass}

As mentioned earlier, one of the MAT program's mainstays is reflective journal writing. Each week, the students are expected to synthesize their readings and experiences, reflect on their learning, and connect this learning to their future classroom. We require students to think critically about current research, trends in education, and pedagogical practice, reflecting on their roles as both student and teacher. Throughout the six-week summer semester, growth in thinking and writing is evident. Initially, some students struggle with reflective writing: they have difficulty being introspective and contemplative, qualities unfamiliar in traditional academic writing. Yet, by the end of the summer, due to consistent practice, feedback, and revision, they are positioned to become more reflective practitioners as they begin their residencies.

Each week, students write an 8-10 page reflection that is graded by a different faculty member each week. This way, the student receives feedback from all the course instructors; likewise, each instructor has the opportunity to read all of the students' writing throughout the semester. We structured this reflection to be a continuous paper: each week, the student begins the next reflection at the conclusion of the previous weeks. In the past, we asked students to keep all reflections in a folder, which was handed in each week, containing all the feedback from other faculty and previous journal entries. Instructors had the opportunity to look back at feedback given in previous weeks to ascertain if students were incorporating prior suggestions to improve their writing. In a sense, it was a running record of their evolution in thinking throughout the semester, an opportunity for them to be metacognitive.

Remote instruction posed a challenge for this practice to continue via paper and folders. Historically, we always used our university's learning management system, Moodle, to house course materials, and record attendance, but always felt grading uploaded student work to be cumbersome and inefficient. However, faced with the dilemma of no longer being able to accept physical paper copies of student writing, 
and understanding the likelihood of our students using Google Classroom in their Residencies in the fall, we decided to have the students submit their reflective journals on this platform. This way, we were familiarizing them with Google Classroom, while allowing us to track comments on a continuous thread of reflective writing. Additionally, the students could respond to any instructor's comments on their journals at any time, providing more opportunities for conversation and communication than ever before.

\section{Reaching Out and Staying Connected}

In a sense, remote instruction opened up more opportunities for engagement than in a face-to-face setting. We found that the Chat function in Zoom became an unlikely community- building tool, as well as a way to reach out to individual students privately during class instruction. During discussions, students would put comments in the chat box in response to something a classmate said or just adding to the conversation without speaking aloud. Second language learners would ask for clarifications on words or their spellings, explanations of idioms, or for a summary of something they did not understand. We noticed that our students would anticipate when an ELL would have difficulty comprehending, and would address those needs in the chat box. This rarely occurred in a face-to-face class: if ELLs had questions or misunderstandings, most would usually wait until the end of class to privately ask the instructor, and the other students in the room were oblivious to these ELLs' difficulties with language and comprehension. (Perhaps, because these ELLs had access to multiple instructors, they felt more comfortable asking questions in real time, without interrupting the discussion or lesson, and could better advocate for themselves or articulate their questions better in writing.) The Chat function allowed for more interaction and engagement between the students, similar to old-fashioned note passing in class publicly and privately.

Additionally, Chat was beneficial for the instructors. We could send private messages to the students if we wanted to check in with them, ask if they were having difficulty, or arrange a meeting. This function offered an alternative to pulling a student aside before or after class, but also provided a discrete opportunity to address negative student performance or inattention during class. Chat also allowed for private messages between instructors as reminders, prompts, or suggestions. We were able to communicate with each other during instructional time.

\section{Collect the Dots}

Along with the Chat function, we quickly discovered that teaching in an online environment meant there were no geographic boundaries we could not cross. In previous years, we hosted one or two local guest speakers, with perhaps one guest speaker Zooming in from a different location. With everyone on the same platform, it became much more natural to invite guest speakers into our learning space to interact with our students. We invited local teacher educators and teachers, experts in classroom management, and even bloggers and entrepreneurs to speak with our students.

The common experience these speakers provided to our cohort served, once again, to strengthen our community of practice. Two speakers in particular provided a common vocabulary that became part of a common understanding. Our entrepreneur shared a set of vocabulary for the teacher candidates to use to think more creatively about their lesson planning process. Phrases like 'collect the dots' (i.e., gain experience in many different fields) and 'creative curiosity' (refers to intentionally exercising our creative thinking in order to innovate) became part of the cohort's common language, a language that seemed owned by and exclusive to them. Our classroom management speaker used the phrase, 'drop the rope' to illustrate the metaphor of playing tug-of-war with a puppy and a rope. She used this metaphor to represent the idea that teachers need to reduce tension in a classroom management situation rather than escalate tension. Like 'collect the dots', 'drop the rope' became a phrase that appeared in the chat or in conversations, usually accompanied by head nods and thumbs up as the group communicated its mutual understanding.

Guest speakers are not an unusual strategy for teachers. We all use them to provide students with an expert point of view. In this particular environment, however, they served the purpose of increasing the bond that existed in our community of practice by providing a shared experience. 


\section{From Campground to Escape Room}

For the thirty years the MAT program was in existence, students participated in a wilderness-area retreat during the first week of the program. This two-day retreat accelerated friendship building and trust among the individuals in the cohort. In the day or two leading up to the retreat, the candidates often acted fairly reserved, likely playing out their version of what they felt graduate school should look and feel like. During the retreat, students participated in trust-building activities, cooperative problem solving, and team building, which really strengthened relationships among the cohort. After the retreat, the faculty liked to joke that they had lost all control of the group as they supported each other, and sometimes challenged the faculty on their curricular decisions. This level of camaraderie was exactly what the program relied on to buoy the candidates as they moved through the intensive summer and rigorous residency. It also set the groundwork for lifelong collegial relationships. In the lead up to the online summer, the faculty struggled to figure out how to replicate exercises that could bring the group together. Ultimately, we had to admit that there was little we could do online to replicate canoeing, hiking, outdoor challenges in the rain, and marshmallow roasts.

So, we started thinking outside the box: what were some other activities, even some online communal activities, that fostered team building? Because we had no access to funding, our options were limited. We were able to identify two free virtual escape room activities that seemed to fill that niche. The most promising escape room was a simulated bank heist that students would have to navigate together to crack a safe in twenty minutes. Each instructor completed this simulation individually and determined it would be a challenging and worthwhile activity for the students to complete in teams, followed by a debrief discussing growth/fixed mindset; challenge level vs. frustration level; teamwork and community building; following directions; accommodations for ELLs; vocabulary; differentiation; and introduction to disciplinary literacies. The escape room activity looked as if it would address many educational objectives and serve as a critical thinking exercise for our students. However, because we sometimes had difficulty reconnecting with the website, we identified a backup escape room activity, based on the Harry Potter books, just in case.

As luck would have it, the bank heist website was under construction the day we planned to have students complete the simulation, so we instructed them to complete the alternate activity instead. During the activity debrief, many students expressed their frustration because they were unfamiliar with the world of Harry Potter: it just was not part of their schema. In fact, some students, which was a popcultural surprise to us, had no idea about this world of magic and muggles. They were completely confused and unable to comprehend the tasks, solve the problems, and save the wizardry relics. Much to our chagrin, we made the assumption that all our students knew about Harry and Hogwarts. Needless to say, our best laid plans flopped. But all was not lost: this was a teachable moment. We were able to debrief with the pre-service teachers, reflect on how lessons do not always go as planned, and discuss adjustments for future activities. This incident also heightened our candidates' awareness of the need to know the cultural backgrounds of their students so that oversights like this are minimized.

\section{A Community Within a Community}

Some of our more vocal critics of the escape room activity were our Chinese language students. Immediately following this activity, the Chinese students asked for a private meeting with the instructors. They shared that this was the first time in the course that they felt untethered and unsupported. Although we work very hard to teach them about American adolescents, American schools, American pedagogy, somehow we missed the mark on Western pop culture. We falsely assumed, or probably took for granted, that everyone was familiar with the wizarding world of Harry Potter. Sometimes, even the most wellintentioned, culturally responsive instructors fumble and unintentionally disadvantage students.

Yet, if there is a silver lining in this cultural oversight, it is this: we created a community of learners who were comfortable enough to speak with us about their experiences and their needs. Rather than just chalk it up to a misunderstanding and wasted activity, our Chinese students advocated for themselves and shared their concerns. We have found that culturally, Chinese students are deferential to their instructors, 
and rarely question or oppose them. This unity showed that they supported one another and were willing to address their instructors when they felt their needs were unmet.

Their self advocacy raised our awareness of the cultural disconnect and motivated us to further differentiate on their behalf. Following this conversation with the students, we began to provide them with all the instructional materials for upcoming lessons a few days prior. This gave them an opportunity to review the slide presentations, videos, and readings ahead of time so they could more comprehensively prepare for class participation.

As the summer program progressed, our support for this community within the community extended to outreach with the Chinese students' families in China. This outreach focused on our support for the students as the national political rhetoric and environment became hostile toward our international Asian students. The students and their families questioned their decisions to pursue teaching careers in the United States, which lead to conversations about their career path within the context of their safety and well-being.

\section{A Country in Crisis}

Our concern for our students' safety and well being expanded exponentially as the black community in the United States fell under siege after the murders of George Floyd and Breonna Taylor. Protestors took to the streets in Black Lives Matter rallies, and the media was saturated with cries for social justice amidst racial unrest and police brutality. This was the undercurrent of our summer semester. Months earlier we had already planned for six hours of diversity and inclusion workshops to take place in mid-July. By this time, our students were primed to talk; they had known each other for three weeks and already expressed concern about wanting to discuss institutional and systemic racism. These workshops were co-facilitated by two faculty members who addressed race and racial identity. Students participated in individual and group activities focusing on an antiracist approach to teaching and learning by examining bias, stereotypes, equity, and access. Our MAT students were eager to have difficult conversations in safe spaces, which prepared them to have these similar conversations with adolescents in their own classrooms.

At the same time, we were experiencing a global pandemic: infection rates of COVID-19 were surging and thousands of people were dying. Anxiety levels were high as uncertainty regarding school reopenings abound. Our students were positioned to begin their residencies in the fall, and too many unknowns were plaguing educators everywhere. To address this issue, and to try and alleviate as many fears and concerns as we could, we incorporated a cooperative learning "teaching in the age of COVID" jigsaw activity in which students read a selection of current event articles related to the reopening of schools, including proposed timelines, technological challenges, and safety measures. Arming students with facts, from both medical and educational professionals, helped equip them for teaching in the fall.

Using the Black Lives Matter movement and global pandemic as backdrops for an induction to the teaching profession allowed us an opportunity to show students the importance of incorporating current events into the curriculum, across disciplines. Being able to have students think critically through meaningful conversations, and exploring different perspectives through diverse voices will position students and teachers to enact change in the world. Also, attending to what is happening in the world around us will help shape informed citizens to participate in our democracy and to protect our environment for future generations. Asking our students to reflect as both learner and teacher gives them a unique perspective.

\section{Alone Together}

The impact of the dual crises was evident in our students' behavior. While they were all committed to preparing for their fall residencies, there was more volatility in the cohort's behavior compared to previous years. It was not unusual for a candidate to, for example, reach a public breaking point while trying to navigate a new app, or go silent after making even a minor misstep in a group interaction. While these situations occur in an in-person classroom setting, Zoom seemed to highlight individual's difficult moments as all eyes turned to their little image on the screen. To combat this tension, the faculty built rituals into the days' lessons that were lighthearted and reinforced the candidates' accomplishments. 
These rituals took many forms. For example, one faculty member taught the candidates different ways to show appreciation when someone added to their learning. Candidates could give a thumbs up, or pat themselves on the back, or they could give a 'round of applause' by clapping their hands and moving them in a circular motion. Candidates also enjoyed 'alligator claps' (opening arms wide and coming together for one big simultaneous clap). While definitely silly, these actions helped lift the mood and modeled strategies the candidates could use in their residencies in the fall.

Another lighthearted strategy was the use of 'teacher hats'. Throughout the summer, faculty would ask the candidates to 'put on their teacher hats' in order to encourage them to think from the perspective of a teacher as opposed to a learner. For some candidates, this is a difficult shift to make, and requires modeling accompanied by many opportunities to succeed. As the summer progressed, the faculty started to encourage candidates to select a hat to keep in their learning space that they could wear when thinking like a teacher. During those moments when they were thinking like teachers, or had achieved a milestone as a group, we all put on our teacher hats to celebrate. As can be seen in the photo, students intentionally chose creative options for their hats to embrace the silliness and join in the sense of community building.

FIGURE 2

\section{STUDENTS WEARING 'TEACHER HATS'}

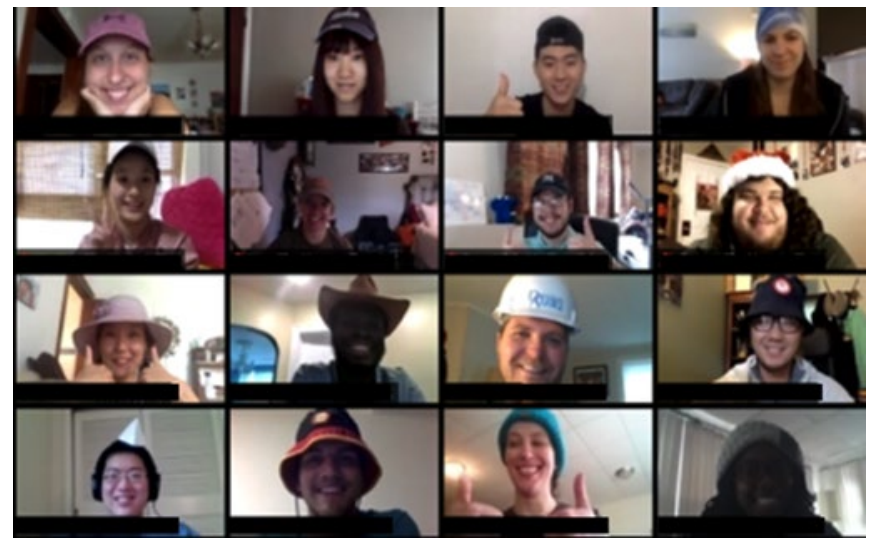

\section{Onions Don't Just Make You Cry}

For the last several years, the onion has been the unofficial mascot of the MAT program. No one is certain how this happened, but the idea is now perpetuated from year to year by the students and faculty. Over the course of the summer program, the onion is referenced frequently because of its obvious metaphorical connections to teaching - sometimes it makes you cry; when well prepared, it becomes sweet and enjoyable; the onion works well with lots of other foods; it will grow in just about any environment even a cold refrigerator drawer; and so on. During the COVID-19 summer semester, the onion took on new meaning as the students inserted our mascot into the pandemic crisis. The photo included here was taken by an MAT student and shared with the class as an expression of how she was feeling at that moment. She expressed her hope, as she placed the onion in the midst of her vegetable garden, and simultaneous fear for the future. These seemingly dichotomous feelings are also expressed by the tears the onion is crying and the smiley face mask the onion is wearing. When discussing metaphors, the onion took on new meaning as a resilient little vegetable that needed special attention to thrive. MAT candidates talked about how the onion sometimes represented them, sometimes their future students. As the summer wore on, the faculty realized that this summer in particular, the onion didn't just make us cry, it brought us together as a community. Conversations around the onion also alerted faculty to students who may need a sidebar conversation or check-in. It became fascinating to witness how focusing on an everyday object such as a yellow onion helped make the implicit explicit. The use of a simple mascot helped the cohort coalesce around ideas and values that would carry them into the difficult 2020-2021 teaching year. 


\section{FIGURE 3 \\ THE MAT ONION MASCOT DURING COVID}

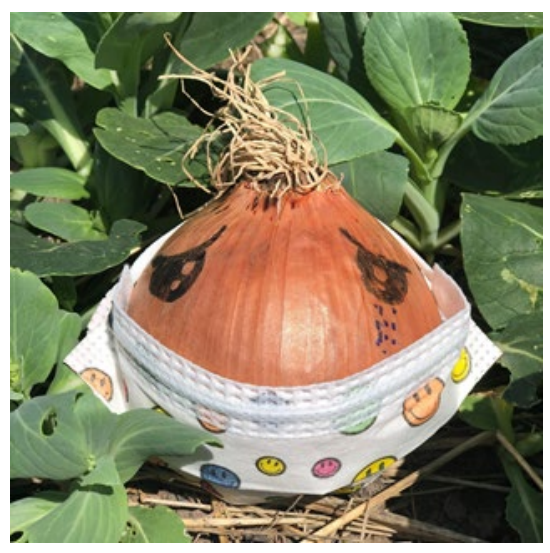

\section{CONCLUSION}

"Life is a series of natural and spontaneous changes. Don't resist them--that only creates sorrow. Let reality be reality. Let things flow naturally forward in whatever way they like." Those words, attributed to Lao $\mathrm{Zi}$, ring true, and have been the guiding force behind our program's transformations. As teacher educators, building a community of practice and fostering students' socio-emotional learning is our raison d'être. This year's challenges forced us to change the way we have been teaching for many years...and that was not necessarily deleterious. In fact, some of these community-building practices made our program even stronger. Our immediate reaction to pivoting to emergency remote instruction was almost crippling, until we realized we could not go back, only forward. And though the way forward was virtually unknown, literally, to many of us, we did what good teachers do: adjust and adapt in the moment. We learned you do not have to be face-to-face to build relationships among a community of learners. We learned that a growth mindset was critical for navigating these uncertain times. We learned we are stronger together. We were reminded, though we've known it all along, it's the teacher who makes the difference, not the classroom.

\section{REFERENCES}

Baran, B. (2014). A case study of online communities of practice for teacher education: Motivators, barriers and outcomes. [Unpublished doctoral dissertation/master's thesis]. The Graduate School of the Natural and Applied Sciences of Middle East Technical University.

Bellocchi, A., Mills, K.A., \& Ritchie, S.M. (2016). Emotional experiences of preservice science teachers in online learning: The formation, disruption, and maintenance of social bonds. Cultural Studies of Science Education, 11, 629-652.

Bouchard, K.L., Hollweck, T., \& Smith, J.D. (2016). Fostering classroom communities through circling with teacher candidates. McGill Journal of Education, 51(3), 1103-1120.

Cooper, J.E. (2007). Strengthening the case for community-based learning in teacher education. Journal of Teacher Education, 58(3), 245-255.

Cramer, K.M., \& Castro-Olivo, S. (2016). Effects of a culturally adapted social-emotional learning intervention program on students' mental health. Contemporary School Psychology, 20, 118-129.

DuFour, R. (2004). What is a "professional learning community"? Educational Leadership, 61(8), 6-12.

Ekici, D.I. (2018). Development of pre-service teachers' teaching self-efficacy beliefs through an online community of practice. Asia Pacific Education Review, 19(1), 27-40.

Elias, M.J., Zins, J.E., Weissberg, R.P., Frey, K.S., Greenberg, M.T., Haynes, N.M., \& Shriver, T.P. (1997). Promoting social and emotional learning: Guidelines for educators. Alexandria, VA: Association for Supervision \& Curriculum Development. 
Garner, P.W., Bender, S.L., \& Fedor, M. (2018). Mindfulness-based SEL programming to increase preservice teachers' mindful and emotional competence. Psychology in the Schools, 55(4), 1-14.

Grossman, P., \& Wineburg, S. (2020). What Makes Teacher Community Different. Center for the Study of Teaching and Policy and Center on English Learning \& Achievement. Retrieved from https://www.education.uw.edu/ctp/sites/default/files/ctpmail/PDFs/Community-GWW-012001.pdf

Ingles, S. (2014 ). The group assessment procedure: Predicting student teaching performance. Journal of Scholastic Inquiry: Educational, 1(1), 120-133.

Kirschner, P.A., \& Lai, K.W. (2007). Online communities of practice in education. Technology, Pedagogy and Education, 16(2), 127-131.

Kitade, K. (2014). Second Language Teachers' Identity Development through Online Collaboration with L2 Learners. CALICO Journal, 31(1), 57-77.

Knight, S.W.P. (2020). Establishing professional online communities for world language educators. Foreign Language Annals, 53, 298-305.

Lave, J., \& Wenger, E. (1991). Situated learning: Legitimate peripheral participation. Cambridge University Press.

Main, K. (2018). Walking the talk: Enhancing future teachers' capacity to embed socio-emotional learning in middle years classrooms. Education Science, 8, 143-157.

Osher, D., Kidron, Y., Brackett, M., Dymnicki, A., Jones, S., \& Weissberg, R.P. (2016). Advancing the science and practice of social and emotional learning: Looking back and moving forward. Review of Research in Education, 40, 644-681.

Reeves, J., \& Le Mare, L. (2017). Supporting teachers in relational pedagogy and social emotional education: A qualitative exploration. The International Journal of Emotional Education, 9(1), 8598.

Shabani, K. (2016). Applications of Vygotsky's sociocultural approach for teachers' professional development. Cogent Education, 3(1), 1-10.

Stipp, B. (2019). A big part of education also: A mixed-methods evaluation of a social and emotional learning (SEL) course for pre-service teachers. Emotional and Behavioral Difficulties, 24(2), 204-218.

Vygotsky, L.S. (1978). Mind in society. Harvard University Press.

Wasko, M.M., \& Faraj, S. (2005). Why should I share? Examining social capital and knowledge contribution in electronic networks of practice. MIS Quarterly, 29(1), 35-57.

Weissberg, R.P., Durlak, J.A., Domotrovich, C.E., \& Gullotta, T.P. (2015). Social and emotional learning: Past, present, and future. In J.A. Durlak, C.E. Domitrovich, R.P. Weissberg, \& T.P. Gullotta (Eds.), Handbook of social and emotional learning: Research and practice (pp. 3-19). The Guilford Press.

Wenger, E. (1998). Communities of practice: Learning, meaning and identity. Cambridge University Press.

Wentzel, K.R. (2019). Introduction to the special issue on social emotional learning. Educational Psychologist, 54(3), 127-128.

Yaeger, D.S. (2017). Social and emotional learning programs for adolescents. The Future of Children, 27(1), 73-94.

Yoder, N. (2014). Teaching the whole child: Instructional practices that support socio-emotional learning in three teacher evaluation frameworks. American Institutes for Research.

Zheng, Y., Li, L., \& Zheng, F. (2011). A conceptual model of online community of teaching practice for preservice teachers. In Y. Wu (Ed.), Computing and intelligent systems (pp. 394-400). Springer. 